\title{
Intellectual disability-obesity-brain malformations-facial dysmorphism syndrome
}

INSERM

\section{Source}

INSERM. (1999). Orphanet: an online rare disease and orphan drug data base. Intellectual disability-obesity-brain malformations-facialdysmorphism syndrome. ORPHA:352530

Intellectual disability-obesity-brain malformations-facial dysmorphism syndrome is a rare, syndromic intellectual disability primarily characterized by moderate to severe intellectual disability, true-to-relative microcephaly and brain abnormalities including a thin corpus callosum, cerebellar hypoplasia, cerebral white matter hypoplasia and multi-focal hyperintensity of cerebral white matter on MRI. Obesity and distinctive craniofacial dysmorphism (including brachycephaly, round face, straight eyebrows, synophrys, hypertelorism, epicanthus, wide and depressed nasal bridge, protruding ears with uplifted lobe, downslanting corners of the mouth) are additional features. 